\title{
Student Videos as a Tool for Elementary Teacher Development in Teaching Engineering: What Do Teachers Notice? (research to practice)
}

\section{Ms. Mary McCormick, Tufts University}

Mary McCormick is a PhD student in STEM Education at Tufts University. She received a BS in Civil Engineering from University of Massachusetts Lowell and an MS in Civil Engineering from Tufts University. Her current research involves exploring how elementary students' nascent resources for engineering design emerge during integrated engineering and literacy activities.

\section{Kristen B Wendell, University of Massachusetts Boston}

Kristen B. Wendell is Assistant Professor of Elementary Science Education in the Department of Curriculum and Instruction and the Center of Science and Mathematics in Context at the University of Massachusetts Boston.

\section{Mr. Brian Patrick O’Connell, Tufts University}

Brian O'Connell received his undergraduate degree in Mechanical Engineering from the University of Massachusetts at Amherst in 2006. He then worked for Kollmorgen Electro/Optical as a mechanical engineer developing periscopes and optrontic masts. In 2011, he returned to academia to pursue his Doctorate in Mechanical Engineering at Tufts University in Medford, Mass. He aspires to become a professor of mechanical engineering after graduation focusing his research in engineering design, educational technologies, and engineering education. 


\title{
Student Videos as a Tool for Elementary Teacher Development in Teaching Engineering: What Do Teachers Notice?
}

\begin{abstract}
The Next Generation Science Standards call for all K-12 students to participate in practices of engineering and to consider core disciplinary ideas of engineering design. This inclusion of engineering in the NGSS heightens the engineering education community's need to develop effective supports for K-12 teachers who are learning to teach engineering. A National Science Foundation supported project at Tufts University's Center for Engineering Education and Outreach aims to provide this support to elementary teachers as they learn to develop and implement integrated engineering and literacy (IEL) activities in their classrooms. As part of the ongoing professional development (PD) for this project, participating teachers discuss instructional practices for creating and implementing literature-based engineering activities in their classrooms. These instructional practices involve attending to student reasoning and fostering student engagement in engineering areas of problem scoping, conceptual planning, and realizing and testing design ideas.

This qualitative research study focuses on elementary teachers' development of instructional practices, including how teachers identify and respond to students' early engineering abilities during IEL activities. Using student video as a tool for investigating elementary teacher noticing in engineering ${ }^{1}$, researchers conducted clinical interviews with in-service elementary teachers as they viewed clips of students at work on an engineering project. Interview transcripts were analyzed using a systematic, iterative process drawing on methods from grounded theory and constant comparative analysis ${ }^{2,3}$. Four themes of teacher attention and three themes of envisioned response emerged from this work. This paper discusses these findings and discusses implications for designing PD aimed at supporting teachers in identifying and responding to student thinking during engineering activities.
\end{abstract}

\section{Introduction}

The Next Generation Science Standards ${ }^{4}$ call for all K-12 students to participate in practices of engineering and to consider core disciplinary ideas of engineering design. This inclusion of engineering in the NGSS heightens the engineering education community's need to develop effective supports for K-12 teachers learning to teach engineering. As part of a National Science Foundation supported project at Tufts University's Center for Engineering Education and Outreach, this work explores a professional development (PD) program that is geared towards supporting teachers as they learn to facilitate integrated engineering and literacy (IEL) experiences in their classrooms. Our central objective in this PD program is to help teachers attend to student thinking during engineering activities, to respond in ways that sustain student 
agency and engagement, and to foster student development of engineering reasoning and practices, such as problem framing, conceptual planning, and realizing and testing design ideas.

Over the last three years, our research team has collected video data during IEL activities in classrooms of rural, urban, and suburban communities in Massachusetts. Our collective analyses of student artifacts and video data evidence the emergence of three patterns of reasoning and engineering practice that we recognize as being productive beginnings of engineering. The three patterns, or "key aspects," include framing problems, conceptual planning, and realizing and testing design ideas. In framing engineering problems, elementary students may gather and use information to establish the scope of the problem they are solving, consider multiple sets of criteria and constraints, and take on different perspectives to determine what might count as a satisfactory solution. As they engage in conceptual planning, students may articulate their own explicit ideas about how an engineering problem can be solved, often bringing mathematical and scientific reasoning to bear on comparing and evaluating multiple options and solutions. While some students may recognize a need to plan before begin building, others may create and revise plans as they begin working with building materials. Throughout this process, students may realize and test their design ideas, identifying and applying evaluation criteria, often implicitly, to determine the effectiveness, functionality, or viability of their solution. Students' evaluations may include conducting physical tests, collecting and analyzing information from tests or other forms of feedback (e.g., peer review, class discussions), and using results and feedback to refine their designs. In these ways, students' engineering design decisions are not based on any prescribed way of engineering, but instead reflect their reasoning, evaluations, and logic in achieving design objectives. Thus, students' productive beginnings of engineering not only encompass their abilities to engage in these patterns of reasoning and practices, but also involve their recognition of a need to invoke such abilities.

The aim of our PD is to support teachers in strengthening their abilities to teach engineering during IEL activities; in this, teachers are not only developing engineering lessons, but recognizing opportunities for students to engage in problem framing, conceptual planning, and realizing and testing design ideas. Further, during PD, teachers work towards developing strategies for responding to students to foster their engagement, while sustaining student agency and attention to the task. For example, a teacher may notice one group of students testing the strength of a material by applying weights and may ask what they have found from their tests and how it will solve the problem. In this response, the teacher is providing a scaffold for students to reflect on what they have learned about material properties or structural integrity by prompting reasoning for how these concepts may inform the design, while supporting studentdriven investigations and testing. In another instance, the teacher may notice a group in the classroom whose engineering solution involves imaginary or magical features, such as buttons for invisibility or time travel. The students' assumptions in this example negate their need to engage in problem framing, conceptual planning, and realizing and testing their design ideas. To 
reorient students, the teacher may respond by asking questions related to functionality, feasibility, and the design context, but refrains from telling the students how to solve the problem. While these two hypothetical examples show very different situations, both illustrate ways in which the teacher is attending to students' engineering reasoning and actions, and responding to sustain students' pursuits.

In this qualitative study, we investigate what elementary teachers, before initial PD and IEL experiences, notice during engineering design activities, and how they see themselves interacting with students. To gain insight to elementary teachers' development of instructional practices in engineering, we conducted clinical interviews using student video as the subject of discourse. The interviews were conducted to answer the research question, how do elementary teachers identify and respond to children's engineering in a video episode viewed before formal professional development? In the same way that research on preconceptions about science concepts has informed science curriculum materials, our research aims to inform the formation of professional development materials on elementary engineering. The purpose of conducting pre-PD interviews was to construct a baseline analysis of teachers' responses to student engineering so that we would be better able to tailor professional development experiences to teachers' understandings and approaches.

\section{Theoretical Framework}

Our research framework is in grounded in three areas of literature that collectively inform our approach to analyzing elementary teachers' responsiveness towards children's engineering. First, we draw from a large body of prior work that characterizes the development of expertise in engineering practice ${ }^{5-10}$. For example, work by Atman and colleagues showed that successful experienced engineers tend to spend a substantial amount of time gathering information before fleshing out design ideas ${ }^{6}$, and they evaluate tentative design ideas before implementing them, while novice engineers more often begin right away with a systematic trial-and-error approach ${ }^{5}$.. In his research on expert mechanical engineers, Cross found that they explicitly identify the tensions between their own goals for solving an engineering problem and the clients' requirements for an acceptable solution ${ }^{9}$. They also maintain a focus on physical principles throughout their design process ${ }^{9}$. Discoveries like these about the work of expert engineers help us identify the productive "beginnings of engineering” in children's work.

Second, we invoke and build on previous research on pedagogical content knowledge for teaching engineering. ${ }^{11}$ More specifically, we incorporate research by Hsu, Cardella, and Purzer that investigated teachers' preparation for teaching engineering, ${ }^{12}$ as well as work by Capobianco and colleagues and Nadelson and colleagues on changes in teachers' engineering teaching abilities and attitudes after professional development experiences ${ }^{11,13-16}$.

Finally, our framework is based on and seeks to contribute to literature on teachers' 
"professional vision"17 and "teacher noticing" of student thinking"18-21. Research conducted by Hammer, Coffey, Levin, Sherin, van Es, and others in the fields of math and science teacher education explores what teachers attend to when they analyze student work with colleagues, and examines ways for guiding teachers' attention to the substance of student thinking ${ }^{18}$. For instance, Sherin, van Es, and Han investigated teacher video clubs in mathematics education ${ }^{20,21}$ and showed that when math teachers met regularly to watch and discuss video excerpts, they became more attentive to students' mathematical thinking at the video meetings as well as in their own classrooms $^{22}$.

\section{Research Objective}

Our central aim is to support teachers in creating learning experiences in which student activity reflects disciplinary engineering, and students perceive themselves as both creators and evaluators of engineering design solutions. To achieve this, we designed and implemented an initial three-day professional development workshop for elementary teachers that focused on responding to student thinking in ways that support student agency in engineering design. On the first day of PD workshop, we conducted interviews with each of the teachers (described below). In this study, we analyze the interview data to explore the range of ways in which participating teachers attend to student thinking during an engineering design activity, and how they envision their responses as teachers in these moments. Our hope is that by discerning what teachers notice and how they respond to students during IEL activities, we will be better equipped to develop and implement PD to support teachers.

\section{Methods}

This study is part of a larger qualitative descriptive research project on elementary teacher development in teaching engineering through literature-based activities. In this larger project, inservice elementary teachers first participate in video-based interviews about elementary students' engineering. They next attend a summer PD workshop on developing and implementing integrated engineering and literacy experiences in elementary classrooms. During the workshop, teachers engage in literature-based engineering design challenges, explore other aspects of engineering such as product analysis and the use of a decision matrix, view and discuss video of students' engineering, and review works of children's literature to make initial plans for literature-based engineering activities for their own classrooms. They then refine these plans and implement at least two IEL activities during the academic year with their students. As part of the ongoing PD program, teachers also participate in teacher/researcher monthly meetings to debrief and to view and discuss video from their own classroom activities.

During the academic year, the research team collects multiple forms of data to study the teachers' expectations for and development in teaching engineering. These data sources include pre- 
interviews with teachers prior to the professional development workshop, video recordings of engineering challenges and large-group discussions during the workshop, a post-workshop focus group, classroom observations as teachers implement engineering and literacy activities in their classrooms, post-interviews with teachers after each implementation, and audio recordings of teacher/researcher debrief meetings.

For the study reported in this paper, we focus on data from pre-interviews with teachers prior to the professional development workshop.

\section{Data Collection}

Five elementary teachers participated in the video-based clinical interviews. All five were new to the IEL approach, and were selected as participants because they were the full cohort of teachers new to the project at a summer professional development workshop. In the interviews, the teachers were prompted to describe how they facilitate small group projects in their own classrooms. They then watched an episode of three third-grade students solving an engineering problem based on a non-fiction text about the colonial era in America. Finally, they shared what they noticed about the students' engineering work in the video episode and how they might respond to the students in the episode. Two researchers, who were the lead facilitators for the summer professional development workshop, conducted the interviews. Both interviewers followed the same interview protocol, which is based on the questions used in Sherin and colleagues' teacher video clubs ${ }^{20,21}$. They conducted the interviews the first morning of the workshop. The length of the interviews ranged from 12 to 24 minutes including three minutes for viewing the video. The full interview protocol is included in the appendix.

In the video clip, a group of three male students in third grade are involved in an IEL design task based on the nonfictional text If You Lived in Colonial Times, by Ann McGovern. In the book, McGovern presents information about the lifestyles of people who lived during colonial times (1565-1776), including what they did for work, the children learned in school, the clothes they wore, the food they harvested and ate, and the types of farm chores they did every day using simple tools $\mathrm{s}^{23}$. The third grade students' engineering task is to design and construct something that would "make life easier" for people in the colonial era. The third graders in the three-minute video clip have been designing and constructing a water filter using cardboard, tape, coffee filters, cloth, and cotton balls, and are testing the different filter materials (coffee filters, cloth, and cotton balls) by pouring water through the filters. In the clip, they have run into a problem: their "pipe," a paper towel tube with tinfoil around it, leaks. This problem escalates social tension in the group: while boy wants to start over, the other does not think they will have time to make a new one. We selected this clip because it shows not only evidence of productive engineering engagement (realizing, testing, and evaluating ideas), but also challenging teaching moments that often occur during IEL activities. 


\section{Data Analysis}

We analyzed the interview transcripts using a systematic, iterative process based on Glaser and Strauss's methods of grounded theory and constant comparative analysis ${ }^{2}$. We first

comprehensively reviewed and discussed all transcripts from the video analysis task ${ }^{2}$. Drawing on tools from discourse and interactional analysis ${ }^{24-27}$ and using evidence from both verbal and non-verbal aspects of the data, ${ }^{27-29}$ we identified recurring themes in what the teachers said they noticed about the video and in how they envisioned responding to the students in the video. From these themes we defined one set of codes for teacher attention and another set of codes for envisioned response. Two researchers then conducted line-by-line consensus coding to assign each utterance to a teacher attention category, and when applicable (i.e., when the teacher spoke about a possible way to interact with the students), an envisioned response category. Finally, we populated a matrix where we crossed the teacher attention dimension with the envisioned response dimension. We listed the envisioned response categories as rows of the matrix, and the teacher attention categories as columns, and placed utterances in the appropriate cells of the matrix. This matrix allowed us to see how teachers tended to envision their response to students when they were attending to particular aspects of the student video.

\section{Findings}

The coding analysis of teacher interview transcripts evidenced the emergence of four themes in teacher attention, including social dynamics, engineering solutions, student thinking, and teacher moves, and three themes in teachers' envisioned responses, including provide engineering knowledge, empathize with student perspective, and direct student work. The teacher attention themes were based on the following patterns: attention to students' interactions with each other and abilities to work in groups (social dynamics); focus on aspects of the solution itself, such as functionality (engineering solutions); interpretation of or curiosity about students' reasoning or understanding (student thinking); and interest in or questions about how a teacher in the classroom could or should have been orchestrating the activity (teacher moves). Similarly, the three themes of envisioned response were based on the following patterns in teachers' descriptions: giving the students a specific piece of information to complete the engineering task (provide engineering knowledge); generating possibilities of how the students in the video might be making sense of the activity (empathize with student perspective); and assessing the students' work and proposing ways for them to proceed (direct student work).

Here we present our teaching-noticing matrix (Table 1) which intersects the categories of teacher attention with their envisioned responses to students. This matrix illustrates the interaction of teacher attention and envisioned response: while teachers' attention at different moments inevitably influences how they envision themselves responding, their envisioned responses, in 
Table 1: Teacher Framing Matrix

\begin{tabular}{|c|c|c|c|}
\hline & $\begin{array}{c}\text { Authoritative Instructor } \\
\text { and Assessor }\end{array}$ & $\begin{array}{l}\text { Holder of Engineering } \\
\text { Knowledge }\end{array}$ & $\begin{array}{c}\text { Empathizer with } \\
\text { Students' Perspectives }\end{array}$ \\
\hline & $\begin{array}{c}\text { Values student assessment } \\
\text { and right way to do } \\
\text { something }\end{array}$ & $\begin{array}{c}\text { Values students' } \\
\text { engineering ideas and } \\
\text { perspectives }\end{array}$ & $\begin{array}{c}\text { Values students taking up } \\
\text { the IEL project and how } \\
\text { they do so }\end{array}$ \\
\hline $\begin{array}{c}\text { Social Dynamics in } \\
\text { Student Groups } \\
\text { Focus on student } \\
\text { collaboration and } \\
\text { group dynamics } \\
\text { while working on an } \\
\text { engineering design } \\
\text { project }\end{array}$ & $\begin{array}{l}\text { K: They all had, they all had- } \\
\text { They all had an unspoken } \\
\text { job. ... } \\
\text { That's why I usually will give } \\
\text { them like if- In groups of } \\
\text { fours, they'd be four jobs, and } \\
\text { sometimes I think I had to } \\
\text { keep all four of them together, } \\
\text { but switch up the job for each } \\
\text { one, just to see how it affects- }\end{array}$ & $\begin{array}{l}\text { G: Well, it seems like they } \\
\text { were working well together. } \\
\text { That they were } \\
\text { understanding- understanding } \\
\text { like what engineers do, and } \\
\text { that they were trying to solve } \\
\text { a problem. }\end{array}$ & \\
\hline $\begin{array}{c}\text { Students' } \\
\text { Engineering } \\
\text { Solutions } \\
\text { Focus on student } \\
\text { decisions involved } \\
\text { in their engineering } \\
\text { process and solution }\end{array}$ & $\begin{array}{l}\text { G: But I would want to see if } \\
\text { the dirty water, like with } \\
\text { something in it to see. To see } \\
\text { if the cotton really absorbed } \\
\text { some of the dirt. }\end{array}$ & $\begin{array}{l}\text { L: My guess is that they had } \\
\text { read about that stuff, learned } \\
\text { about that during a lesson, } \\
\text { and then they were talking } \\
\text { about, you know, what would } \\
\text { you have done if you } \\
\text { would've had to build your } \\
\text { own water filter, and then } \\
\text { let's try and see if we can do } \\
\text { that, and that makes sense to } \\
\text { me that they would kind of } \\
\text { integrate that way, um. }\end{array}$ & \\
\hline $\begin{array}{l}\text { Students' Thinking } \\
\text { Focus on student } \\
\text { concerns about } \\
\text { what engineering is, } \\
\text { what the teacher } \\
\text { wants, and their } \\
\text { playing the } \\
\text { "classroom game". }\end{array}$ & $\begin{array}{l}\text { V: That's, yeah that's } \\
\text { interesting because how } \\
\text { would they know it's actually } \\
\text { filtering anything? I mean } \\
\text { maybe if they mixed it with, I } \\
\text { don't- soil or something. } \\
\text { Sand. I don't know. They } \\
\text { would know it's filtering the } \\
\text { water out. }\end{array}$ & $\begin{array}{l}\text { N: I like the idea of how the } \\
\text { guy- the little boy said that } \\
\text { engineers don't always stick } \\
\text { with the first thing that they } \\
\text { make, and so that's true, I } \\
\text { mean that's with anything. }\end{array}$ & $\begin{array}{l}\text { V: And he's saying, 'Well we } \\
\text { can't throw it away!' I think } \\
\text { he was the one that said,' We } \\
\text { can't throw it away. Mrs. } \\
\text { Mellon said we can't throw it } \\
\text { away,' and the other little boy } \\
\text { said, 'No, we're just } \\
\text { improving it. That's what } \\
\text { engineers do.' Which was } \\
\text { great. I mean those are the } \\
\text { comments you want to hear } \\
\text { from kids. }\end{array}$ \\
\hline $\begin{array}{c}\text { Teacher Role } \\
\text { Focus on organizing } \\
\text { the engineering } \\
\text { activity and } \\
\text { assessment of } \\
\text { student } \text { work }\end{array}$ & $\begin{array}{l}\text { K: Um. Well, usually in a } \\
\text { classroom it's a question of } \\
\text { time, anyway. You know, no } \\
\text { matter how much time you've } \\
\text { spent, there's no time to start } \\
\text { over. }\end{array}$ & $\begin{array}{l}\text { V: Well how do they go } \\
\text { about picking this? Why this } \\
\text { one? You know, so maybe } \\
\text { reflect on it. Tell me why you } \\
\text { selected this as opposed- I } \\
\text { don't know if they had a } \\
\text { choice. identifying those } \\
\text { materials I think is important } \\
\text { because it'll drive the project. }\end{array}$ & \\
\hline
\end{tabular}


turn, are geared towards influencing social dynamics, engineering solutions, student thinking, and teacher roles (i.e., the four areas of teacher attention). Following the matrix, we provide case studies of three of the teachers to demonstrate three different ways in which teachers' attention to student video and their envisioned responses (italicized in analysis) interact with each other. Through these case studies we illustrate aspects of our analysis, while drawing fuller characterizations of teachers' interactions with engineering situations.

\section{Case 1: K, Grade Five}

A prevalent theme that emerged during interviews was teachers' frequent attention to the social dynamics, particularly in how students collaborate while working on an engineering design project in a group. For instance, in responding to an open-ended prompt, "What was funny or interesting?", K was drawn to the students' role taking, as shown in the following.

"They all had, they all had — They all had an unspoken job...

That's why I usually will give them like if - In groups of fours, there'd be four jobs, and sometimes I think I had to keep all four of them together, but switch up the job for each one, just to see how it affects."

At this moment, K's teacher attention was on social dynamics. While recognizing the need for student ownership and responsibility, she attended primarily to students' abilities to work on teams and to assume roles. What $\mathrm{K}$ noticed about social dynamics immediately led her to an envisioned response of directing student work. Without even being prompted to do so, she shifted from commenting on the video to describing how she tends to facilitate student learning by managing social dynamics. For K, managing social dynamics (assigning roles) is, in part, the teacher's responsibility. The response that K envisioned allowed her to provide direction (rearranging groups), but also accounted for the students' perspectives (challenges in teamwork). When asked explicitly how she would interact with the students in the video, K's initial attention to social dynamics cued her curiosity for how students may be reasoning about the activity:

"I like when you just go and ask them questions, you know, you don't direct them, and say, 'Well, why don't you do this?' That's not what it's about — It's about having them figure it out. Whether they do or they don't, you know. What do you think would happen if you...? You know, and even that might be a little too much direction."

K's envisioned response involved the dynamic interplay between enacting a teacher role and attending to student thinking; she assumed students may need some direction, but was more inclined to create opportunities for students to develop their own understandings. Although she took a top-down approach in managing group work, $\mathrm{K}$ positioned the students as being "epistemic agents" "30,31, recognizing that they are capable of building knowledge togetheras opposed to receiving content from her. Her envisioned response embodied aspects of provide engineering knowledge and direct student work, in that she wanted to provide students with an 
array of directions for their engineering work. She did not aim to direct students towards one correct solution or process, but rather demonstrated a tacit recognition that students are capable of navigating their own paths, and assumed an instructional role as enabling them to do so.

K consistently envisioned this kind of response across learning situations. Earlier in the interview, when prompted to talk about her general teaching approach during engineering activities, she described her actions:

"I like to go around and make sure they're working, you know, as they work I like to let them go. What I've found, generally, is, I will put the directions on the board, so if they're not listening, or if they don't catch the whole thing, there's your step by step."

Based on K's description, teaching engineering is a balance of providing students with responsibilities while attending to their needs for direction and instruction. By providing students with the skeletal structure for learning, built from her directions and guidance in establishing group dynamics, she allows them the freedom and flexibility to create, explore, and "figure it out."

Case 2: G, Grade Four

Similarly, after watching the video, $G$ was initially drawn to the social dynamics; however, she exhibited differences in her attention and envisioned responses. For G, resolving social dynamics did not involve reassigning roles; instead, it meant understanding how the students were making sense of the learning experience. When prompted with "What stands out?" in the video, G demonstrated her proclivity to understand what students may be trying to do:

"Well, it seems like they were working well together. That they were understanding - understanding, like, what engineers do, and that they were trying to solve a problem."

She later added that she didn't think the boy would want to change their original plan because that was how he understood directions. As she described,

"I think that he thought that they couldn't, that they had to stick with their original plan and they couldn't like deviate from it. But I don't - I don't think that he was opposed to it. I think that it was more, what was right and wrong, what the teacher said...Or maybe he was worried about having a final product, or he was worried that, oh it has to work no matter what. 'We planned this, it has to work. If it doesn't, we have to make it work."”

While $\mathrm{G}$ was interested in the social dynamics, she demonstrated stability in her attention to student thinking and was less concerned with providing information or instruction to students. Her envisioned response of empathizing with student perspective allowed her to gain insight to students' interactions and challenges, both in developing a "final product" and working with each other. She did not assess the students, but instead tried to identify and understand the cause 
of their struggle, their perceptions of the task objective, their assessments of staying on task, and how their concerns may have stirred emotions - why one boy is "worried." G's attention and her envisioned response during the video watching enabled her not only to interpret what students are doing, but also to perceive their reasoning and impetus for engaging in certain ways. When asked about her own classroom practices, she described that she likes "to be in the (student) group." Instead of assuming a teacher role or acting authoritatively, she put herself in the students' positions to understand and to scaffold their sense-making.

\section{Case 3: V, Grade Three}

While $\mathrm{V}$ also attended to social dynamics of the students in the video, her primary focus was the engineering solution itself (i.e., a water filter). When prompted with "What did you notice, or what stands out?" V first asked "How do they know the water's filtering?" She then continued to make sense of the filtration mechanism:

"That's, yeah, that's interesting because how would they know it's actually

filtering anything? I mean maybe if they mixed it with, I don't- soil or something.

Sand. I don't know. They would know it's filtering the water out."

After asking whether they developed a blueprint, $\mathrm{V}$ tried to discern the students' rationale for making their decisions, as shown in the following exchange with the interviewer.

$\mathrm{V}$ : And materials. I mean I couldn't understand why they wanted to keep adding

foil, so it wouldn't leak? Is that what he said?

Interviewer: Yeah.

$\mathrm{V}$ : Was there anything underneath that foil or was it just the cotton ball?

Interviewer: It was, um, a paper towel tube, cardboard.

$\mathrm{V}$ : Well, they might want to consider something that's waterproof. A different material.

After viewing the video, $\mathrm{V}$ oriented to aspects of the students' thinking about their engineering solution: she questioned the method of evaluating functionality ("how would they know it's filtering"), the effectiveness of the testing solution ("soil or sand"), and the students' selection of materials ("why they wanted to keep adding foil," "might want to consider something that's waterproof'). Her interest in students' reasoning and decisionmaking were spawned by her curiosity to understand the filtration mechanism. Further, when prompted by the question of how she might "do assessment in this sort of activity," $\mathrm{V}$ focused on how she would assess the project based on engineering criteria, rather than describing how she would evaluate her students' learning of engineering.

$\mathrm{V}$ : And the reliability of their project - I mean, how well did it work for them?

Interviewer: So, by reliability, you mean like the project working? Doing what it's supposed to do?

V: Yeah. And how do you know it did what it did? You know, 'cause my first question is, how do you know it filtered that water? 
In her sense of an engineering design activity, $\mathrm{V}$ prioritized the functionality and reliability of engineering solutions as she would assess them before trying to understand how the students were assessing their own projects. We believe that her questions regarding the filtration mechanism were in service of helping her develop an informed response for directing student work. While we had initially assumed that this response would be coupled with providing engineering knowledge, V's attention to her own students' thinking later in the interview evidenced a slightly different approach. When asked about her own approach to teaching engineering, $\mathrm{V}$ described,

"And it's amazing just to listen to their processes and, you know, if a ship doesn't float, then I'll stop and say, "Okay, engineers, now let's give some recommendations to this engineer. How can he improve or she improve her ship model?" So the ideas come from the kids..."

In her reflection, we noticed a discontinuity between her attention and envisioned response when prompted by student video, and her attention and response to her own students. In the former, she seemed focused on understanding an engineering solution, whereas in the latter, she evidenced curiosity in student thinking ("listen to their process") and strategic teacher moves (i.e., prompting a recommendations session). Moreover, her envisioned response in each of these situations reflected the dynamics of her attention: when focusing on the engineering solution, $\mathrm{V}$ saw herself responding by directing student work and by providing engineering knowledge, but when she was focusing on student thinking and teacher moves, she aimed to direct student work by first gaining a deeper understanding of students' ideas, or empathizing with students' perspectives.

\section{Discussion}

In this study, we described our initial step in investigating how in-service teachers attend and respond to classroom-based engineering design activities, specifically how they envision their interactions with students, before a formal PD experience. Our investigation involved showing a video episode of students doing engineering and conducting clinical interviews with the teachers. In our qualitative analysis, we noticed emergent themes in the dynamics of teachers' attention and envisioned responses to students during an engineering activity. From our analysis, we highlight two salient findings. The first is that the focus of teachers' attention mediates which aspects of the classroom engineering activity they wish to influence at any given moment, and in turn, their desired influence mediates their envisioned response to students. This finding is consistent with what we know about teaching in general; in a given classroom activity, a teachers' attention is likely spread across and shifting between multiple aspects of the activity. Subsequently, teachers respond to students in ways that enable them to solve immediate classroom issues such as social conflicts within student groups, as well as to achieve long-term learning goals, which may range from ensuring students know specific content to unpacking students' ideas and making sense of their reasoning. For example, $\mathrm{K}$ attends to social dynamics, 
hopes to influence these dynamics, and envisions a response involving assigning student group roles. However, when attending to social dynamics she also implies that certain dynamics might support students' independent reasoning better than others, and she envisions another response that might help students "figure it out" on their own.

The second finding we wish to highlight is that the use of student video during interviews may provide a spectrum of teachers' expectations for engineering activities, but may also inaccurately represent their responses during their own classroom experiences. For instance, V's attention on students' engineering solutions in the video seemed to drive her envisioned response of directing student work. When she described her own classroom, however, she reported attending to student thinking, and described a response that would hold students accountable as creators and evaluators of their own engineering design solutions - a central goal of our PD program. The two situations (i.e., the engineering activity in the video episode and the engineering activity $\mathrm{V}$ implemented in her classroom) thus evoke different types of responses from V: in the former, she prioritizes understanding the solution itself, while in the latter, she supports students in constructing their own explanations for functionality. We posit that there are many possible reasons for this discontinuity, such as her relationships with the students, her comfort with and knowledge about the different engineering tasks, and how she was interpreting her own experience as an interviewee during the first day of PD. It is possible, for instance, that she believed the interviewers were more interested in what she knew about engineering, and therefore oriented to the engineering solution, as opposed to her thoughts about what the students were doing and how she naturally responds in similar situations.

\section{Conclusion}

Moving forward in this research, our next step is to evaluate the utility of student video as a tool for understanding teachers' development in engineering. We plan to achieve this by analyzing the classroom data and follow-up interview data we have collected from teachers who have participated in PD (such as K, G, and V). We believe it is crucial to account not only for not only how teachers are interpreting the engineering situation in the video episode, but also for how they are forming a sense of the video watching activity. For instance, by analyzing data from V's classroom and conducting video-based interviews about her own kids, we hope not only learn more about how she interacts and responds to students' thinking during engineering activity, but also how to adapt video-based interviews to more closely reflect and enable connection to teachers' own classroom experiences.

We have found that video-watching can reveal a spectrum of teachers' expectations for teaching engineering, and we anticipate that future work will uncover the affordances of video-watching for teacher development in teaching engineering. Video-watching can be a tool that supports teachers' productive identification of and response to the beginnings of engineering in students' 
work. We do not believe that the matrix of teacher attention and response generated in this study is comprehensive, nor is it generalizable; rather, we see it as being an approach to understanding how a specific group of teachers approach engineering situations. By gaining a deeper sense of how this group of teachers view engineering activities, we are better prepared to tailor future PD experiences to support them in identifying the beginnings of engineering in their students, responding in ways that sustain student agency, and fostering student engagement in engineering practices, such as problem framing, conceptual planning, and realizing and testing design ideas.

\section{Acknowledgements}

This study was supported by the National Science Foundation under grant DRL-1020243. Any opinions, findings, and conclusions expressed in this material are those of the authors and do not necessarily reflect the views of the National Science Foundation.

\section{Bibliography}

1. Sherin M, van Es E. Using Video to Support Teachers' Ability to Notice Classroom Interactions. J Technol Teach Educ. 2005;13(3):475-491.

2. Glaser BG, Strauss AL. The Discovery of Grounded Theory: Strategies for Qualitative Research. New York, New York, USA: Aldine de Gruyter; 1967:1-10.

3. Strauss A, Corbin J. Grounded Theory Designs. In: Basics of qualitative research: Techniques and procedures for developing grounded theory.; 1998.

4. National Research Council. Next Generation Science Standards. Washington, D.C.: The National Academics Press; 2013.

5. Ahmed S, Wallace KM, Blessing LTM. Understanding the differences between how novice and experienced designers approach design tasks. Res Eng Des. 2003;14:1-11.

6. Atman CJ, Adams RS, Cardella ME, Turns J, Mosborg S, Saleem J. Engineering Design Processes : A Comparison of Students and Expert Practitioners. J Eng Educ. 2007;96(4):359-379.

7. Bucciarelli L. Designing Engineers. Cambridge, MA: MIT Press; 1994.

8. Crismond DP, Adams RS. The informed design teaching and learning matrix. J Eng Educ. 2012;101(4):738-797.

9. Cross N. Expertise in Design: an Overview. Des Stud. 2004;25(5):427-441. 
10. National Research Council. The Engineer of 2020. Washington, D.C.: The National Academics Press; 2004.

11. Hynes M. Teaching Middle-School Engineering: An Investigation of Teachers' Subject Matter and Pedagogical Content Knowledge. 2009.

12. Hsu M-C, Cardella ME, Purzer S. Assessing elementary teachers' design knowledge before and after introduction of a design process model. In. In: In Proceedings of the 117th American Society for Engineering Education Annual Conference and Exposition, Louisville, KY. Louisville, KY; 2010.

13. Capobianco BM, Diefes-Dux HA, Mena IB. Elementary school teachers' attempts at integrating engineering design: Transformation or assimilation? In: Proceedings of the 118th American Society for Engineering Education Annual Conference and Exposition. , Vancouver, British Columbia; 2011.

14. Nadelson L, Seifert AL, Hettinger JK. Teaching by design: Preparing K-12 teachers to use design across the curriculum. In: ASEE Annual Conference and Exposition, Conference Proceedings. 119th ASEE Annual Conference and Exposition. San Antonio, TX; 2012.

15. Hsu M-C, Cardella ME. Engineering Design Process Knowledge: Comparison Between Teachers New to Engineering and More Experienced Eeachers. In: In Proceedings of the 120th American Society for Engineering Education Annual Conference and Exposition. Atlanta, GA.; 2013.

16. Yoon SY, Evans MG, Strobel J. Development of the Teaching Engineering Self-Efficacy Scale (TESS) for K-12 Teachers. In: Proceedings of the 119th American Society for Engineering Education Annual Conference and Exposition. San Antonio, TX: American Society for Engineering Education; 2012.

17. Sherin MG. The development of teachers' professional vision in video clubs. In: Goldman R, Pea R, Barron $\mathrm{B}$, Derry S, eds. Video research in the learning sciences. Lawrence Erlbaum Associates; 2007:383-395.

18. Hammer D, Van Zee EH, eds. Seeing the Science in Children's Thinking: Case Studies of Student Inquiry in Physical Science. Portsmouth, NH: Heinemann; 2006.

19. Levin DM, Hammer D, Coffey JE. Novice Teachers' Attention to Student Thinking. J Teach Educ. 2009;60(2):142-154. doi:10.1177/0022487108330245.

20. Sherin MG, Han SY. Teacher learning in the context of a video club. Teach Teach Educ. 2004;20(2):163183.

21. Van Es EA, Sherin MG. Mathematics teachers' "learning to notice" in the context of a video club. Teach Teach Educ. 2008;24(2):244-276.

22. Sherin MG, van Es EA. Effects of Video Club Participation on Teachers' Professional Vision. $J$ Teach Educ. 2009;60(1):20-37.

23. McGovern A. If You Lived in Colonial Times. St. Louis, MO: Turtleback Books; 1964.

24. Goodwin C. Action and Embodiment Within Situated Human Interaction. J Pragmat. 2000;32:1489-1522.

25. Goodwin C. Participation, Stance and Affect in the Organization of Activities. Discourse Soc. 2007;18(1):53-73.

26. Jordan A, Henderson. Interaction Analysis: Foundations and Practice. J Learn Sci. 1995;4(1):39-103. 
27. Tannen D. What's in a Frame? Surface Evidence for Underlying Expectations. In: Tannen D, ed. Framing in Discourse. Oxford University Press; 1993:14-56.

28. Hammer D, Elby A, Scherr RE, Redish EF. Resources, framing, and transfer. In: Mestre JP, ed. Transfer Of Learning from a Modern Multidisciplinary Perspective.; 2005:89-120.

29. Goffman E. Frame Analysis: An Essay on the Organization of Experience. Contemp Sociol. 1974;10(1):60.

30. Scardamalia M, Bereiter C. Knowledge building: Theory, pedagogy, and technology. In: Sawyer RK, ed. The Cambridge handbook of the learning .... Cambridge University Press; 2006:97-114. doi:10.1598/RT.61.2.5.

31. Scardamalia M, Bereiter C. Higher Levels of Agency for Children in Knowledge Building: A Challenge for the Design of New Knowledge Media. J Learn Sci. 1991;1(1):37-68. 


\section{Appendix}

\section{Questions for Video-Based Interviews with Teachers New to the Project}

\section{Part 1. Your Project Approach}

The first thing we'd like to talk about is your general approach to project work in your classroom.

(A) When you're walking around the classroom while students are working on projects, or looking over their work, what would you say you're hoping to see?

(B) How would you say you generally interact with students while they are working on projects?

a. How about when you DON'T see what you're hoping to see?

b. How about when you DO see what you're hoping to see?

(C) How do you assess or evaluate group project work, if at all?

\section{Part 2. Noticing the Students}

The next thing we'd like to talk about is what you notice about the students in this clip. We're going to show about 3 minutes of video (two separate clips), and then ask you for your thoughts on what stands out to you, and whether anything is confusing or surprising.

[Show the cotton-ball water filter clips.]

(1) Looking at the video, what do you notice about the students? What really stands out to you about these students or their work?

(2) What, if anything, was or is confusing or surprising to you about what the students were doing or saying?

(3) What do you notice in this video about the ways that literacy and engineering are being integrated (or not integrated) by the students?

(4) Do you have any lingering questions about what the students were saying or doing?

[Pose these probing questions as needed:]
a. What did the students says?
b. What did the students say about
c. What did the students understand?
d. What did the students understand about__ ?
e. What was the students' approach to _ ?
f. Why did students focus on _ ? 
Reference: Sherin, M.G., Han, S. Y. (2004). Teacher learning in the context of a video club. Teaching and Teacher Education, 20, 163-183.

\section{Part 3. Reflecting on Teacher Moves}

The third thing we'd like to talk about is the moves you might make as a teacher related this clip - the ways you might respond to or think about the students' ideas, to what they are doing and saying.

(5) Everyone does engineering-and-literacy projects differently; we don't know the best way to interact with these students, and are just curious about your thoughts. What are some possible ways for a teacher to respond to or interact with these students?

(6) If you could step in and ask these students some questions, what might you ask them?

(7) How do you think these students might react?

[If time remains, ask questions 8 and 9.]

(8) I know we haven't talked much about this type of project, but if you were going to assess or evaluate or provide feedback on this IEL work, what would you be interested in assessing, or what might that look like?

(9) You're just starting out with this, but what questions - if any - do you have about how to make decisions about interacting with students when teaching engineering/literacy lessons?

[Pose these probing questions as needed:]
a. What did you say?
b. What did you say about?
c. What did you say in response to ?
d. How did you set up _ _ ?
e. How did you facilitate ? 